\title{
Estrutura Social e Segregação em São Paulo: Transformações na Década de 2000*
}

\author{
Eduardo Marques
}

Professor livre-docente do Departamento de Ciência Política da Universidade de São Paulo (USP) e pesquisador do Centro de Estudos da Metrópole (CEM-USP). São Paulo, SP, Brasil. E-mail: ecmarq@uol.com.br

\begin{abstract}
região metropolitana de São Paulo é caracterizada por intensa seA gregação residencial, construída ao longo das décadas de sua formação e consolidação como metrópole. Entretanto, as intensas transformações econômicas, políticas e demográficas vivenciadas pelo país e por sua mais importante cidade nas últimas décadas fariam esperar diversas mudanças nesses padrões. Esta é, na verdade, a expectativa das hipóteses existentes na literatura sobre as transformações recentes em grandes cidades, apontando na direção da polarização da estrutura social e dos espaços, com aumento da segregação, como veremos mais adiante. Este artigo testa tais hipóteses utilizando dados dos Censos de 1991, 2000 e 2010 para analisar a segregação residencial na metrópole paulistana em período recente, assim como suas transformações na última década. Os resultados apresentados ao longo do texto indicam fortes mudanças, mas nem sempre na direção esperada pelos debates da área.
\end{abstract}

O tema foi já vastamente explorado pela literatura desde os anos 1970. Uma primeira geração de trabalhos analisou o fenômeno de forma

\footnotetext{
* Este artigo se insere em pesquisa mais ampla do Centro de Estudos da Metrópole (CEM) e sua escrita se beneficiou de discussões envolvendo vários colegas. Destaco em especial Rogério Barbosa, Ian Prates, Carolina Requena, Danilo França e Telma Hoyler, a quem agradeço pelos comentários específicos ao conteúdo deste artigo.
}

DADOS - Revista de Ciências Sociais, Rio de Janeiro, vol. 57, no-3, 2014, pp. 675 a 710. 
narrativa, qualitativa ou monográfica em estudos clássicos como Camargo (1976), Kowarick (1979) e Bonduki e Rolnik (1982). Mais recentemente, partindo dos dados censitários de 1991 e 2000, diversos estudos revisitaram o tema de forma quantitativa, construindo índices de segregação para renda e escolaridade (Torres, 2005), tipificando situações de vulnerabilidade (CEM, 2004) ou analisando segregação por classe, considerando diversas classificações ocupacionais (Taschner e Bógus, 2000; Marques, Bichir e Scalon, 2012; Marques e Scalon, 2009; Preteceille e Cardoso, 2008).

O presente artigo se inscreve nesse debate. Em primeiro lugar, investigo as principais transformações na estrutura de classes, dialogando com as hipóteses mais importantes da literatura internacional a respeito dos impactos sociais da reestruturação produtiva recente e sobre as mudanças na segregação residencial em grandes cidades. De uma forma geral, não se pode afirmar a presença de polarização social, embora a hipótese de profissionalização tampouco seja confirmada completamente. Em seguida, analiso os padrões de segregação em 2000 e 2010, discutindo as suas mais importantes características em termos de concentração espacial e de localização. De forma sintética, a metrópole paulistana continua intensamente segregada com um claro padrão de evitação entre grupos sociais posicionados nos polos da estrutura social, o que é compatível com a literatura existente. Entretanto, embora as transformações ocorridas na década tenham trazido maior homogeneidade nas áreas habitadas pelas elites, a heterogeneidade das periferias tendeu a aumentar.

O artigo é dividido em três partes, além desta Introdução e da Conclusão. Na primeira, discuto os principais elementos conceituais envolvidos com a análise a partir da literatura. Em seguida, investigo a estrutura social e o padrão de segregação residencial em 2000 e 2010, considerando renda e classes sociais. Na terceira seção, desenvolvo uma tipologia de espaços naqueles anos, de forma a capturar as mudanças espaciais ocorridas. Ao final, resumo os principais achados do trabalho.

\section{O DEBATE SOBRE A SEGREGAÇÃO RESIDENCIAL EM SÃO PAULO}

Como é amplamente conhecido, São Paulo é intensamente segregada, a exemplo de outras cidades brasileiras e latino-americanas (Villaça, 2000; Carvalho, Souza e Pereira, 2004; Píres, 2009; Centeno, 2009; 
Dureau e Vanegas, 2009). Estudos clássicos sobre a cidade já apontavam esse padrão de segregação como uma de suas mais importantes e constitutivas características (Camargo, 1976; Kowarik, 1979). Também desde os anos 1970 a estrutura geral da segregação residencial foi caracterizada como radial e concêntrica (Bonduki e Rolnik, 1982). Nessa estrutura, as amenidades, os serviços e os grupos sociais mais ricos localizavam-se no centro da metrópole. O espaço a partir deste organizava-se em gradientes de crescente esvaziamento e precariedade na direção das periferias (Bonduki e Rolnik, 1982), lugar de sociabilidade ao mesmo tempo específica e similar ao restante da cidade (Durham, 1988).

Mais recentemente, enquanto algumas análises ressaltaram a permanência dessa estrutura (Taschner e Bógus, 2000; Maricato, 2003; Villaça, 2000), outras destacaram a crescente heterogeneidade do território metropolitano, em especial nas periferias (CEM, 2004; Marques e Torres, 2005), mas também nas favelas (Marques e Saraiva, 2005), a exemplo de estudos sobre o Rio de Janeiro (Valladares e Preteceille, 2000). Evidências trazidas por estudos etnográficos reforçaram essas análises ao indicar significativa heterogeneidade nos espaços periféricos (Feltran, 2011). É interessante observar que essa heterogeneidade já era destacada classicamente (Bonduki, 1991; Vetter, Massena e Rodrigues, 1979), embora a leitura predominante até recentemente destacasse a homogeneidade das periferias.

Para os debates existentes sobre a São Paulo anterior ao ano 2000, essa heterogeneidade teria sido o produto de diversos processos combinados. Por um lado, seria produzida por um deslocamento na ação do Estado desde a redemocratização, impulsionado pela ação de movimentos sociais urbanos e por burocracias técnicas reformistas em um ambiente de competição partidária organizada crescentemente pela política eleitoral (Faria, 1992; Marques e Bichir, 2003). Isso teria levado ao crescente provimento de políticas e serviços, mesmo para os mais pobres dentre os pobres (Figueiredo, Torres e Bichir, 2006). Por outro lado, a composição social desses espaços periféricos também teria se alterado, com intensas mudanças demográficas (Baeninger, 2012), na pobreza (Marques, 2010) e na estrutura social, que teria se transformado de forma lenta, mas contínua. Por fim, esses padrões de heterogeneidade teriam sido reforçados pela disseminação de novos produtos habitacionais ligados a condomínios fechados localizados em espaços periféricos, em particular para grupos sociais ricos (Caldeira, 2000). 
Essas transformações até o final dos anos 1990 dialogam de forma contraditória com os debates internacionais existentes sobre as grandes tendências urbanas das últimas décadas. Podemos resumir os trabalhos internacionais sobre o tema em dois grupos. Um primeiro conjunto envolve a discussão sobre a reestruturação produtiva ocorrida desde os anos 1970 e suas consequências sobre as cidades, a partir de contribuições fundadoras como Sassen (1991) e Leborgne e Lipietz (1990), apenas para citar duas das tradições mais influentes (e distintas). Um segundo grupo de estudos se insere mais claramente na tradição de análises sobre segregação residencial no espaço, um tema canônico nos estudos urbanos desde os trabalhos pioneiros da Escola de Chicago (Park, Burgess e MacKenzie, 1925) e dos primeiros esforços de mensuração do fenômeno (Duncan e Duncan, 1955). Embora resenhar essas duas tradições esteja fora dos objetivos (e das possibilidades) deste artigo, uma rápida recuperação dos argumentos recentes é importante, pois estes informam as principais hipóteses existentes sobre as transformações ocorridas nas últimas décadas.

Sassen (1991) sustentou que as transformações do capitalismo introduzidas desde os 1970 pela abertura de mercados e pela reestruturação produtiva teriam concentrado as atividades de comando do mundo dos negócios nas grandes cidades, com o consequente esvaziamento de atividades secundárias, ligadas mais claramente à produção fordista. As estruturas sociais de tais metrópoles teriam sofrido processos de polarização, visto que os postos de emprego intermediário típicos da indústria teriam praticamente desaparecido. Em seu lugar teriam surgido dois grupos distintos de ocupação - empregos de grande qualificação e remuneração, em especial nas finanças e nos serviços produtivos, e postos de trabalho em serviços destinados às pessoas de baixa qualificação e remuneração. O resultado geral teria sido de polarização de ocupações, de rendimentos e da estrutura social como um todo. O surgimento de um grupo de super-ricos, assim como de atividades globalizadas capazes de pagar elevadíssimas rendas da terra, "espacializariam" essa polarização social com a criação de bolhas imobiliárias e de grandes projetos de renovação urbana. Embora Sassen (1991) tenha criado a hipótese para Nova Iorque, Londres e Tóquio, esta logo se propagou para muitas outras cidades (Knox e Taylor, 1995).

Partindo de premissas teóricas muito distintas associadas à teoria da regulação, Leborgne e Lipietz (1990) chegaram a um diagnóstico similar. Os autores sustentaram que a crise do fordismo dos anos 1970 e 
1980 nas economias centrais do mundo capitalista gerou diversas respostas dos atores econômicos e governamentais, a maior parte delas organizadas em torno de formas diversas de flexibilização. Estas envolveriam as relações entre firmas, os contratos de trabalho e os processos propriamente fabris, com inúmeras consequências para o capital, o trabalho e as estruturas jurídicas e ideológicas. O que mais nos interessa aqui, entretanto, diz respeito novamente a um diagnóstico de polarização, tanto em termos da estrutura social, quanto no sentido geográfico, com a concentração territorial de atividades e de riqueza nos locais já privilegiados.

Em ambos os casos, portanto, previa-se, como resposta ao crescimento das atividades terciárias ligadas ao comando dos negócios, polarização social e espacial, esta última como consequência das novas dinâmicas de produção do espaço e dos projetos de renovação urbana.

Essas hipóteses têm sido objeto de crítica desde então, em especial pelos debates recentes sobre segregação residencial em grandes metrópoles, o que nos leva a uma rápida recuperação deste segundo debate. É preciso apontar inicialmente que certas partes das hipóteses descritas anteriormente resistiram melhor ao tempo do que outras. Por um lado, o surgimento de um grupo social de super-ricos e de um mercado para promoção imobiliária orientada para atividades de comando dos negócios parece ser consensual. Este processo tem tido grandes consequências espaciais sobre os mercados de terras, a habitação e as políticas urbanas, levando a inúmeros projetos de renovação urbana (Fainstein, 2008), assim como a importantes processos de gentrificação (Butler, 1997) em cidades de todo o mundo.

A hipótese da polarização social, diferentemente, tem sido duramente criticada, pois os efeitos locais dos processos globais parecem variar substancialmente. Segundo alguns autores, os diferentes regimes de Welfare medeiam a influência de processos globais (Hamnett, 1996a; Vaattovaara e Kortteinen, 2003). Como consequência, os mercados de trabalho podem sofrer processos de depreciação, melhora ou estabilidade das ocupações, assim como polarização propriamente dita (Prates e Barbosa, 2013). Para muitos, as dinâmicas recentes seriam marcadas na maior parte dos casos pelo crescimento significativo das ocupações de natureza profissional, assim como pelo desenvolvimento de uma série de novas posições intermediárias na estrutura ocupacional de 
cidades como Londres (Hamnett, 1994, 1996b), Paris (Preteceille, 1995), Tóquio (Fujita e Hill, 2012) ou Oslo (Baum, 1999).

Portanto, em termos de estrutura social, temos como hipótese a testar em São Paulo não apenas a ocorrência de polarização, mas também a profissionalização da estrutura ocupacional.

Também parece consenso que o rebatimento espacial das transformações produtivas sobre os tecidos urbanos é mediado por várias dinâmicas e estruturas, diferentemente da hipótese original de Sassen (1991). Em cidades como Atenas (Maloutas, 2007), Budapeste (Kovacs, 2012) e Paris (Preteceille, 1995) as histórias e estruturas urbanas tiveram importância primordial para construir a situação atual, enquanto em Madri os mercados locais de terras e de habitação desempenharam um papel fundamental (Dominguez, Leal e Goytre, 2012). Processos políticos e políticas públicas locais parecem ter sido fundamentais em diversos locais como Londres (Hamnett, 1994, 1996b), Paris (Preteceille, 2006), Copenhagen (Andersen, 2012) e Helsinque (Wessel, 2000), assim como nas diversas cidades estudadas pelo projeto Urbex (Musterd, Murie e Kesteloo, 2006). Testar a existência de polarização espacial em São Paulo, portanto, representa uma segunda importante tarefa analítica.

De que forma então o debate internacional sobre segregação pode nos informar sobre os processos em curso nas metrópoles brasileiras? Uma excelente e atualizada revisão em 11 cidades pode ser encontrada no livro editado por Maloutas (2012). O autor lista grandes tendências observadas, que dialogam com os resultados que apresento nas próximas seções. Em primeiro lugar, como já destacado, tendências globais não necessariamente se verificam localmente, visto que processos locais influenciam sobremaneira os resultados observados. Na maior parte dos casos, o principal eixo de segregação é socioeconômico e, embora dimensões étnico-raciais se façam presentes, superpõem-se àquela segregação. Neste particular, em geral os ricos são mais segregados do que os pobres, apesar dos debates usualmente destacarem principalmente os segundos. Os níveis de segregação dependem muito das políticas estatais, mas não necessariamente da forma prevista originalmente por seus formuladores. Além disso, Maloutas (2012) sustenta que se observa na maior parte das cidades um aumento da diferenciação social dos lugares com uma crescente aproximação espacial de grupos sociais diversos, sendo os condomínios fechados e a gentrificação 
apenas partes deste processo. Por fim, reduções na segregação não necessariamente significam redução da desigualdade ou maior contato entre grupos sociais.

Estes resultados sugerem um conjunto importante de hipóteses para o estudo da segregação em São Paulo, mas antes de discutirmos a segregação, precisamos recuperar os processos econômicos que a emolduram desde os anos 1990. A abertura comercial ocorrida ao longo da década levou a intensos processos de reestruturação produtiva na metrópole paulistana. Com relação às atividades produtivas, a exemplo de várias grandes cidades dos países centrais, a presença relativa da indústria se reduziu, sendo substituída pelo comércio e pelos serviços, em especial às empresas (Comin e Oliveira, 2010). Na década de 2000, os chamados serviços prestados a empresas foram responsáveis pela geração de cerca de 800.000 postos de trabalho, ficando atrás apenas do setor de comércio e distribuição (Marques, Barbosa e Prates, 2013). Esse fenômeno, entretanto, não encontra paralelo com a desindustrialização observada em centros produtivos clássicos de outros países. Isso porque grande parte das atividades se deslocou para um entorno da chamada macrometrópole, que engloba as regiões contíguas de Campinas, São José dos Campos, entre outras, no processo denominado por Campolina Diniz e Campolina (2007) de desconcentração concentrada. Embora a centralidade da região metropolitana na economia nacional tenha se alterado, a tendência foi mais de superposição de funções econômicas do que de esvaziamento ou substituição. A metrópole associa hoje atividades de comando sobre o mundo dos negócios com atividades produtivas diretas (Campolina Diniz e Campolina, 2007; Comin e Oliveira, 2010). Como veremos a seguir, esses processos de superposição são visíveis nas próprias transformações ocorridas na estrutura social (lentas, mas de clara direção).

Como não poderia deixar de ocorrer, essas transformações econômicas geraram importantes consequências sociais. O desemprego cresceu e a formalização dos postos de trabalho e as remunerações médias caíram de forma quase contínua entre meados dos 1990 até 2002. Como resultado, a pobreza se elevou durante o mesmo período, após ter se reduzido de forma importante, mas pontual, com a estabilização econômica de 1994. Após 2003, todos esses vetores tenderam a se inverter, com a pobreza e o desemprego declinando e a formalização e os salários médios aumentando. 
De que forma estas transformações impactaram a estrutura social na metrópole? Inicio a próxima seção pela discussão das transformações gerais ocorridas na estrutura de classes.

\section{A ESTRUTURA SOCIAL E A SEGREGAÇÃO EM SÃO PAULO}

Para analisar a estrutura de classes, utilizo a classificação social gerada a partir dos dados de ocupação presentes nos Censos de 1991, 2000 e $2010^{1}$. A análise segue uma longa tradição de estudos na sociologia urbana que operacionaliza o conceito de classes sociais partindo de agrupamentos de categorias ocupacionais (Preteceille, 1995). Utilizo aqui a classificação EGP (Erikson, Goldthorpe e Portocarrero, 1979), adaptada para o caso brasileiro e para o Censo de 2010 segundo os procedimentos metodológicos registrados em Barbosa e Marschner (2013). Esta classificação é baseada em uma combinação de distinções entre trabalho manual/não manual, rotina/não de rotina, qualificações e controle e hierarquia sobre o processo de trabalho (contrata trabalho/assalariado/autônomo). Basicamente, as ocupações listadas nos dados da amostra do censo, seguindo a Classificação Brasileira de Ocupações ( $\mathrm{CBO})$, são reclassificadas nas classes definidas previamente, segundo as definições da EGP. O trabalho permite diferentes níveis de agregação e de detalhamento das classes, cuja utilização envolve basicamente trade-offs entre detalhamento/precisão e legibilidade/análise. Foram calculadas 11 classes EGP, porém três classes rurais foram retiradas da análise pela pequena presença na metrópole (proprietários de estabelecimentos agrícolas, autoempregados na agricultura/trabalhadores de subsistência e trabalhadores manuais na agricultura).

Vale dizer que, para a análise da estrutura social, utilizo dados de ocupação para os anos 1991, 2000 e 2010, construindo um quadro das transformações em duas décadas. Para o estudo da segregação residencial, entretanto, comparo apenas informações relativas a 2000 e 2010, pois infelizmente os dados disponibilizados pelo Instituto Brasileiro de Geografia e Estatística (IBGE) para o Censo de 1991 não permitem a identificação das áreas de ponderação (AP) - unidade de análise de maior desagregação das informações de ocupação (constantes apenas na amostra do censo).

A distribuição da população ocupada pelas classes EGP, de 1991 a 2010, é apresentada no Gráfico 1. Como se pode ver, as classes mais 


\section{Gráfico 1}

Distribuição das Classes EGP

(RMSP, 1991, 2000 e 2010)

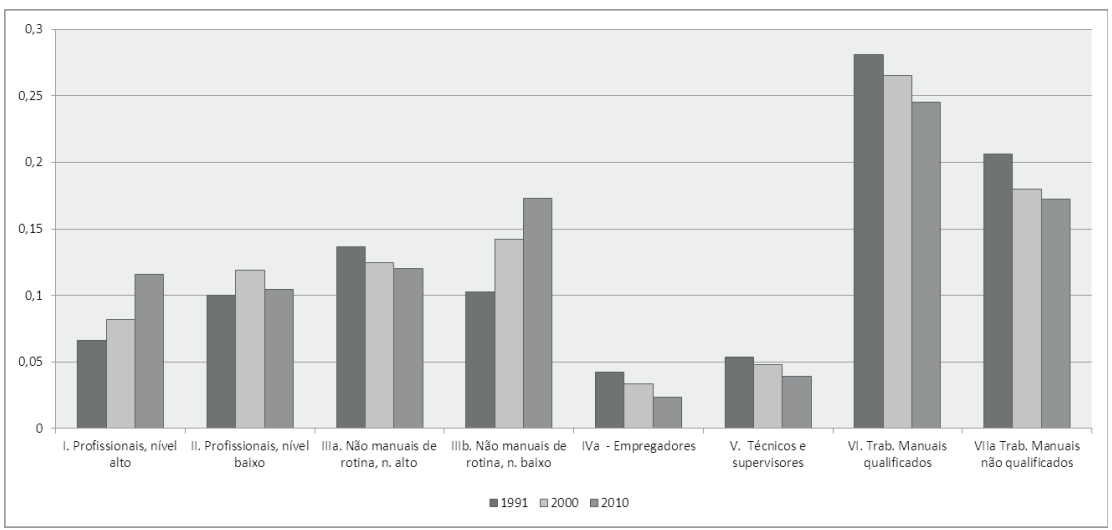

Fonte: Censos IBGE, 1991, 2000 e 2010. Elaboração de Barbosa e Marschner (2013).

frequentes referem-se aos trabalhadores manuais - qualificados e não qualificados, seguidos dos trabalhadores não manuais de rotina, níveis baixo e alto. Em um terceiro patamar encontram-se os profissionais níveis alto e baixo.

Ao longo do tempo, entretanto, os profissionais tendem a aumentar a sua participação, enquanto os trabalhadores manuais qualificados e não qualificados reduzem suas presenças relativas, embora essas duas classes continuem sendo predominantes em 2010. Os trabalhadores não manuais de rotina nível alto tendem à manutenção ou a uma pequena redução que pode se dever à variação amostral. Os trabalhadores não manuais de rotina nível baixo, por outro lado, apresentam clara tendência de crescimento. Ao final do período, entretanto, os manuais não qualificados e os trabalhadores não manuais de rotina nível baixo se encontram quase em iguais proporções, o que em certo sentido é emblemático das transformações em curso na parte inferior da estrutura social. Os proprietários parecem se reduzir relativamente, mas o tamanho do grupo é muito pequeno e o resultado pode se dever à variação amostral.

Esse resultado é amplamente contrário ao que seria de se esperar considerando as teorias que associam os processos de reestruturação produtiva com polarização social discutidas na primeira seção deste artigo. Um resultado de polarização seria encontrado se tanto as classes

DADOS - Revista de Ciências Sociais, Rio de Janeiro, vol. 57, nº 3, 2014 
superiores (em especial proprietários e profissionais de nível alto) quanto os trabalhadores manuais desqualificados crescessem, ao mesmo tempo que trabalhadores manuais qualificados e não manuais de rotina de nível baixo diminuíssem. As transformações indicadas no Gráfico 1 são mais compatíveis com a ideia de profissionalização provocada pela reestruturação produtiva, também discutida anteriormente. No entanto, também no caso desta hipótese seria de se esperar uma redução mais significativa dos trabalhadores manuais, em especial dos qualificados. A permanência dessa classe como a mais numerosa na metrópole, mesmo que em queda, associada com o crescimento dos profissionais, é compatível com a interpretação de uma combinação de centralidades econômicas na metrópole paulistana ao fim do período estudado, concentrando novas atividades de comando sobre o mundo dos negócios, mas sem perder completamente sua centralidade fordista anterior.

Observemos agora a segregação residencial. Vale indicar que as informações de ocupação dos censos demográficos estão incluídas apenas na amostra, o que torna as áreas de ponderação (AP) as unidades de análise disponíveis mais desagregadas. Infelizmente, como já assinalado, só é possível desenvolver a análise para 2000 e 2010, em razão da limitação dos dados das áreas de ponderação em 1991. Para permitir a comparação entre aqueles dois anos, construímos uma base cartográfica comparável entre os censos, agregando as 844 áreas de ponderação de 2000 nas 633 áreas de ponderação do Censo de 2010.

Um primeiro patamar de investigação pode ser alcançado pela observação da renda. Primeiramente, podemos analisar a distribuição espacial da renda utilizando o Índice de Moran, indicador de segregação que mede a autocorrelação espacial com relação a alguma variável de interesse. Matematicamente, o índice varia entre -1 e 1, e expressa a correlação entre o valor de uma variável de interesse em cada área e as médias dessa mesma variável nas áreas vizinhas. Quanto mais próximo à unidade, mais forte é a relação (Anselin, 1995). O Índice de Moran para a variável renda do chefe para as áreas de ponderação de 2000 era de 0,704 , o que indica a existência de uma associação geográfica positiva e de intensidade de média a forte. $\mathrm{O}$ mesmo índice para a variável renda do responsável em 2010 alcançava 0,699, praticamente idêntico. Portanto, no que diz respeito à renda, a metrópole apresenta segregação entre média e alta, que permaneceu intocada entre 2000 e 2010. 
Entretanto, os rendimentos nos dão uma medida demasiadamente simples da segregação por grupos sociais. Outro desdobramento mais detalhado diz respeito à segregação por classes sociais, medida pela classificação EGP já comentada anteriormente. Essa informação é apresentada na tabela a seguir, com as mesmas oito classes ordenadas de forma decrescente em termos de rendimentos.

São apresentados dois índices na Tabela 1: o Índice de Moran (IM) e o Índice de Dissimilaridade (ID). A tabela apresenta os dois índices, pois cada um deles tem vantagens e desvantagens. O Índice de Moran é menos sensível aos tamanhos dos grupos, mas tem interpretação menos intuitiva, enquanto o ID sofre a influência dos tamanhos relativos dos grupos. As classes manuais, por exemplo, apresentam Índices de Dissimilaridade muito mais baixos do que seus Índices de Moran, pois representam grupos grandes, que são predominantes em um amplo território, embora concentrados em áreas segregadas (as periferias). A análise, portanto, deve combinar a observação dos dois índices.

Tabela 1

Índices de Moran e de Dissimilaridade por Classes

(RMSP, 2000 e 2010)

\begin{tabular}{l|c|c|c|c}
\hline \multirow{2}{*}{ Classes } & \multicolumn{2}{|c|}{ Índice de Moran } & \multicolumn{2}{c}{ Índice de Dissimilaridade } \\
\cline { 2 - 5 } & $\mathbf{2 0 0 0}$ & $\mathbf{2 0 1 0}$ & $\mathbf{2 0 0 0}$ & $\mathbf{2 0 1 0}$ \\
\hline Proprietários e empregadores & 0,71 & 0,59 & 0,39 & 0,43 \\
Profissionais, nível alto & 0,80 & 0,75 & 0,37 & 0,35 \\
Profissionais, nível baixo & 0,78 & 0,74 & 0,18 & 0,23 \\
Não manuais de rotina, nível alto & 0,61 & 0,46 & 0,12 & 0,10 \\
Técnicos e supervisores & 0,62 & 0,49 & 0,12 & 0,13 \\
Não manuais de rotina, nível baixo & 0,61 & 0,58 & 0,10 & 0,11 \\
Manuais qualificados & 0,68 & 0,73 & 0,16 & 0,15 \\
Manuais não qualificados & 0,60 & 0,66 & 0,15 & 0,17 \\
\hline
\end{tabular}

Fonte: CEM, Barbosa e Marschner (2013) e cálculos do autor, a partir de dados do IBGE.

Observemos primeiro o Índice de Moran. Usualmente considera-se que valores superiores a 0,6 indicam alta segregação. As informações da tabela, portanto, sugerem segregação entre média-alta e alta, em especial para as categorias superiores. Além disso, os números variam pouco, mas predomina pequena redução, exceto nas classes manuais. Por exemplo, o índice dos profissionais de nível alto era de $0,80 \mathrm{em}$ 2000 , e passou a ser de $0,75^{2}$. Isso indica certa redução da concentração 
dessas classes, embora o resultado possa expressar também o aumento proporcional dessas classes na década, como já vimos. No caso dos trabalhadores manuais qualificados e não qualificados, observa-se elevação da segregação (únicos casos de elevação dos Índices de Moran). Como vimos anteriormente, essas duas categorias reduziram a sua presença da década, o que pode ajudar a explicar o aumento da segregação.

As classes médias apresentam os menores índices. Também nessas classes se observam as mudanças mais expressivas, em especial nas dos trabalhadores não manuais de rotina, níveis alto e baixo. Embora essas não fossem as classes mais segregadas em 2000, passaram a ser as menos segregadas em 2010, com índices de 0,46 e 0,58. Veremos que a redução da concentração dessas categorias médias está inserida em uma tendência recente de expansão exatamente dos espaços mistos. Os empregadores e os técnicos e supervisores também apresentaram reduções expressivas, mas este resultado pode expressar apenas variações amostrais, dado o tamanho destas classes.

Observemos agora o Índice de Dissimilaridade (Tabelas 2 e 3). O índice varia entre 0 e 1 e totaliza as diferenças entre as distribuições de atributos de interesse, considerando uma distribuição como referência. Isso pode parecer um pouco obscuro, mas na verdade a sua interpretação é bastante intuitiva, indicando a proporção da população com um atributo de interesse (como certa origem migratória) que deveria ser movimentada espacialmente para igualar a distribuição da população como um todo ou com outro atributo (a população de outra origem, por exemplo). Como consequência, a tabela nos informa que em 2000 $37 \%$ da população de profissionais de nível alto (ou 0,37) deveria ser movimentada para que a distribuição dessa classe fosse igual à da população em geral nas áreas de ponderação. Como se pode ver, encontramos índices de moderados a baixos (entre 0,1 e 0,23 ) tendo o conjunto da população como referência, exceto para profissionais de nível alto $(0,37$ e 0,35 em 2000 e 2010 , respectivamente) e proprietários $(0,39$ e $0,43)^{3}$, não por acaso as classes superiores já apresentavam Índices de Moran muito altos.

Portanto, sob o ponto de vista de ambos os índices, as classes superiores são as mais segregadas ${ }^{4}$ e as demais apresentam graus de segregação entre medianos e altos. Na década, as classes que mais cresceram 
proporcionalmente tenderam a se desconcentrar, enquanto as que se reduziram aumentaram sua segregação.

Estes resultados, entretanto, ainda dizem respeito ao conjunto da metrópole. Podemos também calcular o Índice de Dissimilaridade entre classes, investigando de que forma os grupos sociais se segregam uns em relação aos outros. As Tabelas 2 e 3 apresentam a informação para 2000 e 2010, respectivamente. Exemplificando a interpretação dos indicadores, a Tabela 2 nos informa que o ID entre profissionais de nível alto e trabalhadores manuais qualificados, por exemplo, era de $0,52 \mathrm{em}$ 2000. Isso quer dizer que $52 \%$ dos profissionais de nível alto deveriam ser movimentados em 2000 para alcançar a mesma distribuição dos manuais qualificados. Em 2010, esta proporção caiu para 0,49. O mais alto índice dizia respeito a proprietários e manuais de nível baixo em 2010 - 0,57 - valor bastante elevado. Os índices mais altos diziam respeito, portanto, às elites, tendo as classes inferiores como referência. Por outro lado, os níveis do ID entre grupos médios e inferiores eram entre medianos e baixos.

No entanto, a observação das tabelas ainda nos indica outra dimensão mais importante. Como podemos ver, os índices são perfeitamente ordenados entre as classes. Quando caminhamos à direita nas linhas ou para baixo nas colunas, os índices aumentam para as classes superiores e diminuem para as inferiores. Para as classes médias eles se reduzem e depois aumentam, embora com menor magnitude. Desse modo, os dados sugerem de forma bastante eloquente que, quanto maior a distância social entre classes, maior a segregação. A estrutura da segregação em São Paulo, portanto, é fortemente hierárquica socialmente, em um claro sentido de evitação social. Assim, entre classes de elite, ou entre classes inferiores, os IDs são muito baixos, enquanto crescem muito entre grupos de elite e inferiores. As distribuições espaciais das classes médias são muito mais próximas daquelas dos grupos inferiores do que das elites, reforçando que o tecido metropolitano tende a ser relativamente heterogêneo, exceto pela localização das classes do topo da estrutura social ${ }^{5}$.

Em termos dinâmicos, comparando as duas tabelas, podemos notar que predomina em geral a manutenção dos índices, mas eles tendem a aumentar entre os profissionais de nível baixo e as categorias médias e baixas, assim como entre os proprietários e todas as categorias médias e baixas. Entre profissionais de níveis alto e baixo, os índices diminuem. 
Eduardo Marques

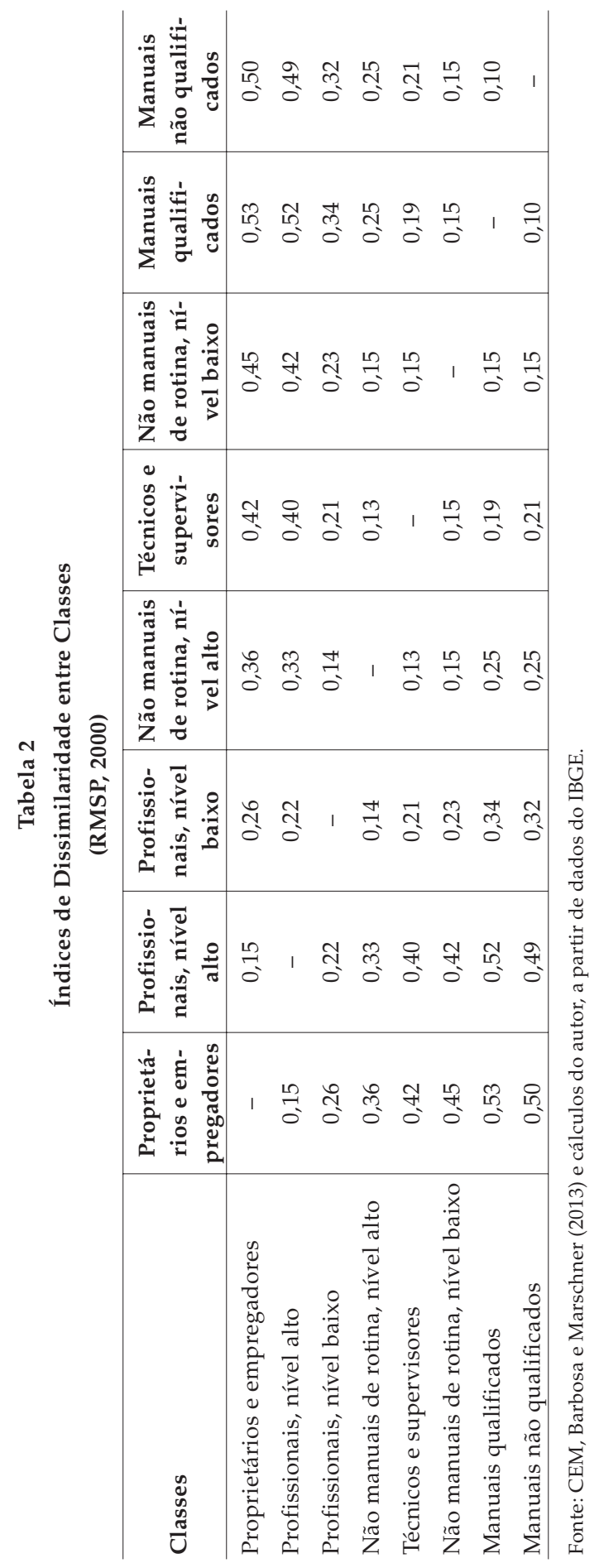

688 DADOS - Revista de Ciências Sociais, Rio de Janeiro, vol. 57, nํ 3, 2014 
Estrutura Social e Segregação em São Paulo

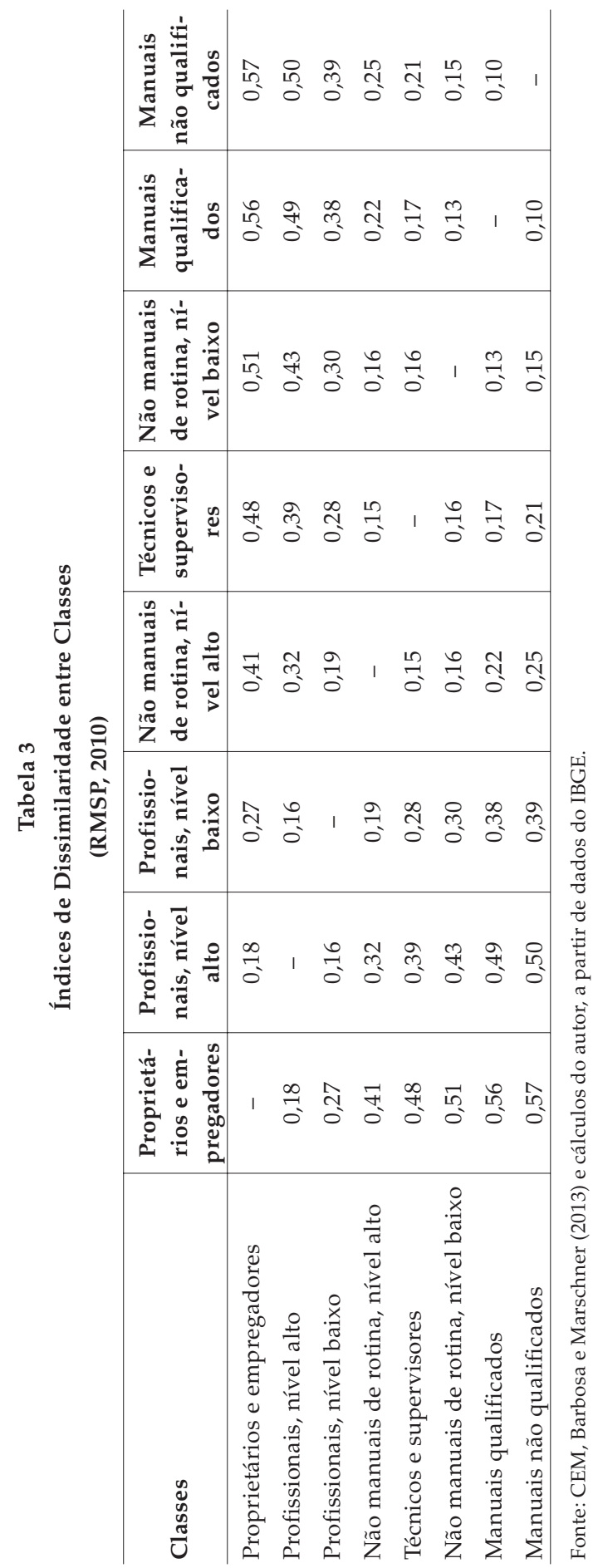

DADOS - Revista de Ciências Sociais, Rio de Janeiro, vol. 57, nํㅡ, 2014 
Portanto, a metrópole paulistana é segregada, em especial no que diz respeito às classes superiores. O conjunto da estrutura de segregação é fortemente hierárquico e as classes médias e inferiores tendem a se misturar mais, mas em espaços não habitados pelas elites. A segregação se manteve em geral estável ao longo da década, embora talvez com aumento da segregação das classes superiores e redução da segregação das classes baixas, que se tornaram mais misturadas com as médias. Observemos agora como esse processo se desdobra nos vários espaços e regiões da metrópole.

\section{OS TIPOS DE ESPAÇOS E SUA DISTRIBUIÇÃO GEOGRÁFICA}

Esta seção explora os detalhes espaciais das dinâmicas gerais da segregação observadas anteriormente. Para tanto, realizo dois exercícios analíticos sucessivos. Primeiro, delimito tipos de espaços em cada momento censitário e analiso as suas transformações ao longo dos anos 2000. Em seguida, investigo os padrões de distribuição geográfica destes espaços utilizando mapas.

\section{Tipos de Espaços}

Para a construção dos tipos de espaços, desenvolvi classificações de unidades espaciais (as áreas de ponderação) a partir das presenças relativas das classes sociais em cada uma delas. Esta tipologia partiu da base cartográfica compatibilizada 2000 / 2010, sendo a distribuição das classes EGP nas áreas de ponderação em 2000 e 2010 submetida a análises fatorial e de cluster. O ponto de partida da análise foi um banco de dados construído de forma que cada área de ponderação entrasse duas vezes, cada uma com as distribuições proporcionais das classes em um censo. Esse procedimento gerou tipos de áreas considerando a composição de classes ali presente, e a utilização conjunta da distribuição dos grupos para os dois censos gerou uma classificação para os dois momentos simultaneamente, garantindo a comparabilidade. A seguir, discuto os resultados, primeiro em termos de distribuição das classes, e depois em termos de mudança dos espaços.

De forma a facilitar a análise de cluster, foi realizada primeiramente análise fatorial da distribuição das classes nas 1.266 "áreas" (633 de cada censo). A análise sugeriu uma grande concentração do fenômeno em dois fatores com autovalores superiores à unidade, que explicavam $78,9 \%$ da variância. O primeiro fator se associava de forma forte (e positiva) à presença de proprietários e profissionais e negativamente aos 
trabalhadores manuais. O segundo encontrava-se associado principalmente com técnicos e supervisores e com trabalhadores não manuais de rotina, níveis alto e baixo.

Em seguida foi realizada análise de cluster das áreas segundo esses dois fatores. Foram testadas várias soluções, mas a que produziu melhor diferenciação entre grupos incluiu cinco grupos ${ }^{6}$. A distribuição das classes para 2000 pode ser observada na Tabela 4. Como se pode ver, à medida que trafegamos do 1 ao 5 , os grupos apresentam proporções decrescentes de classes superiores - proprietários e profissionais - e crescentes de trabalhadores manuais. As classes intermediárias tendem a aparecer mais fortemente nos grupos intermediários, caracterizados por conteúdos mistos, mas com baixa presença relativa dos grupos superiores.

O exercício analítico também gerou grupos para 2010, como demonstrado na Tabela 5. Os resultados apresentaram muita semelhança com os obtidos para 2000, embora as diferenças sejam mais expressivas nos espaços médios-baixos misturados e nos espaços manuais.

Mas será que essas configurações de classe mostram características sociais distintas? Estas podem ser analisadas pelas médias de indicadores não utilizados na análise, inclusive como forma de validar o exercício analítico. A Tabela 6 apresenta a informação, indicando uma clara ordenação decrescente dos tipos de espaço em termos de condições sociais e urbanas. Os rendimentos tendem a cair substancialmente entre os grupos, quando consideramos quocientes em relação à média metropolitana em 2010. É importante notar que os espaços superiores distam muito mais da média do que os inferiores. A composição social também indica população mais rica, menos jovem, menos preta e parda e mais escolarizada nos espaços superiores, com inversão paulatina desses conteúdos quando caminhamos para baixo na tabela.

Com base nos indicadores das tabelas anteriores e em outras variáveis do censo, podemos caracterizar os grupos de unidades em 2010 como se segue:

\section{1) Espaços das elites}

Caracterizava-se pela elevada presença de proprietários e profissionais $(68,0 \%)$, com renda muito alta (quatro vezes a média da metrópole) e escolaridade elevada. A presença de crianças era baixa e a de 
Eduardo Marques

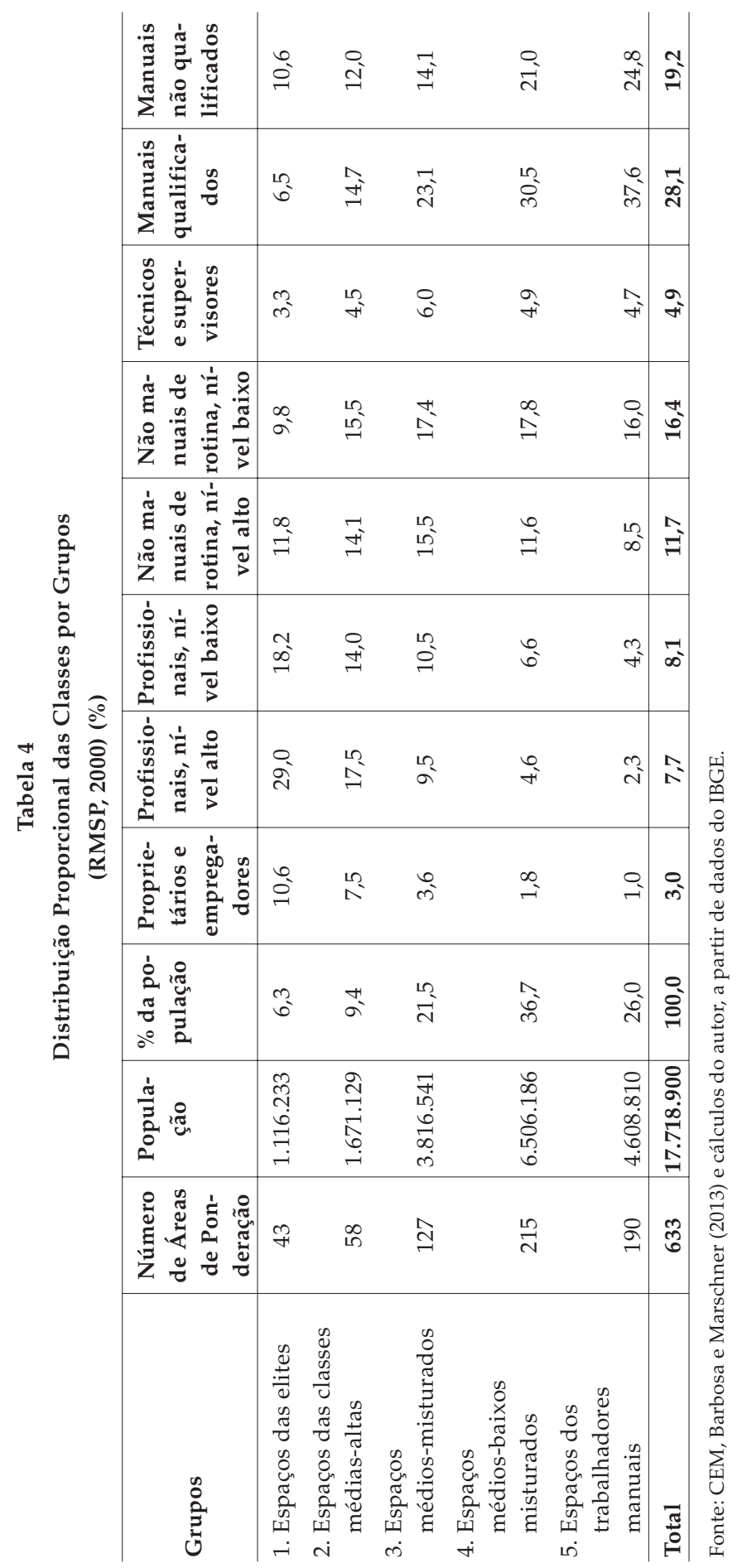

692 DADOS - Revista de Ciências Sociais, Rio de Janeiro, vol. 57, nº 3, 2014 
Estrutura Social e Segregação em São Paulo

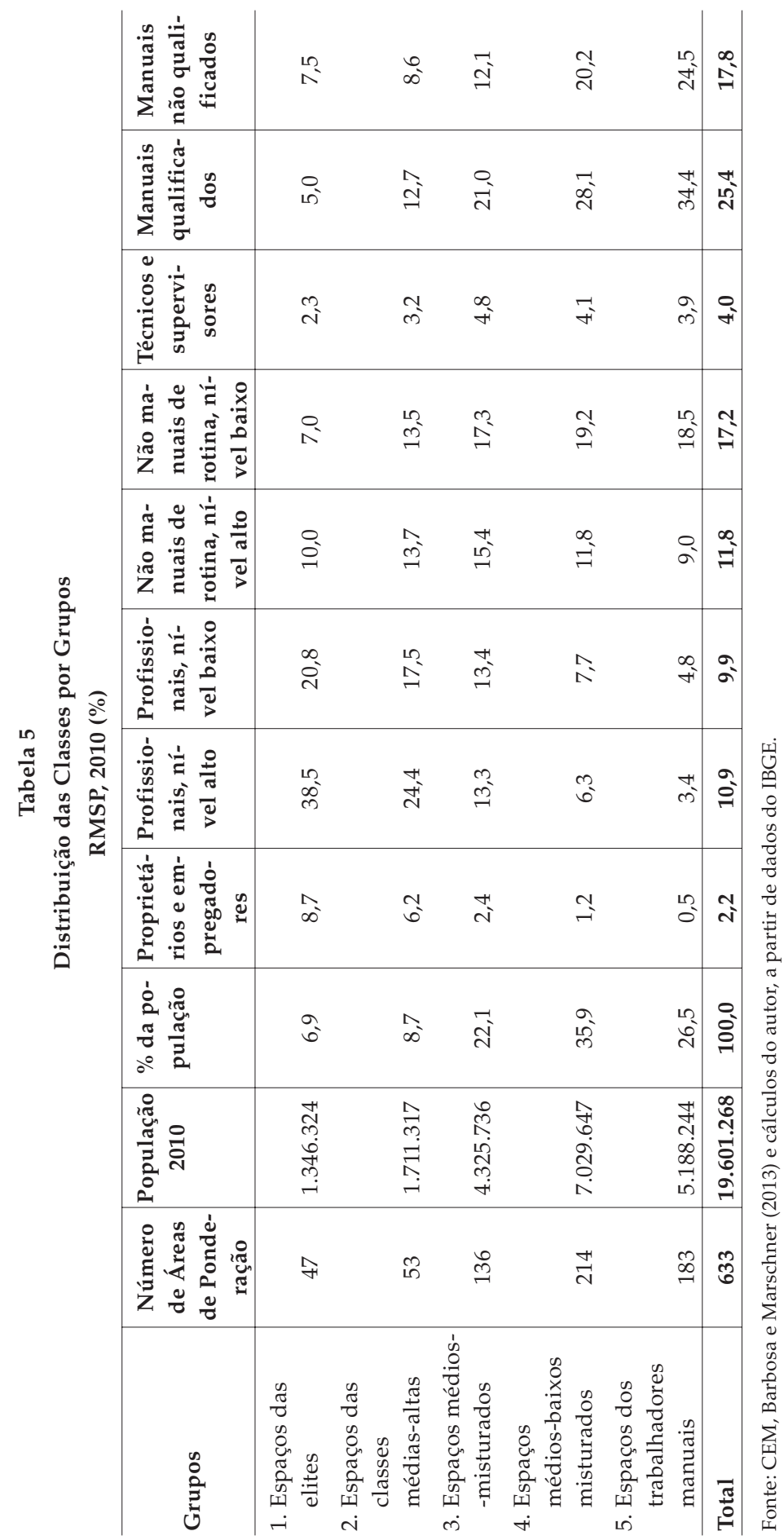

DADOS - Revista de Ciências Sociais, Rio de Janeiro, vol. 57, nํㅗ, 2014 
Eduardo Marques

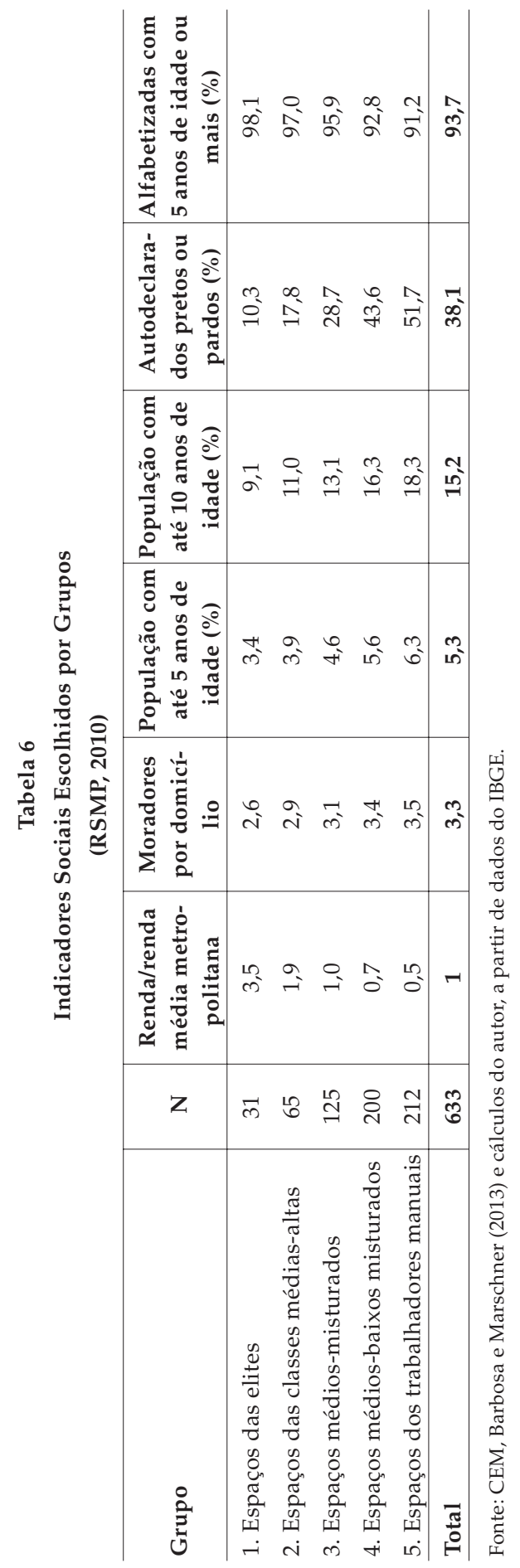

694 DADOS - Revista de Ciências Sociais, Rio de Janeiro, vol. 57, nº 3, 2014 
pessoas autoclassificadas como pretas ou pardas era de apenas um quarto da média da metrópole. Os trabalhadores manuais tendiam a ser residuais $-12,5 \%$. Esses espaços incluíam majoritariamente apartamentos $(69,5 \%)$, densidade domiciliar baixa e acesso à infraestrutura quase completa (coberturas maiores do que $96 \%$ para todos os serviços urbanos). Esses espaços representavam claramente as áreas ocupadas pelos grupos sociais de elite. Perderam população na década de 1990 com taxas médias negativas de $-1,1 \%$ ao ano, mas inverteram as taxas e cresceram a $1,1 \%$ ao ano nos anos 2000 .

\section{2) Espaços das classes médias-altas}

Os proprietários e profissionais também eram predominantes neste grupo, mas já não majoritários - 48,1\%. Além disso, esses espaços também alojavam proporções acima da média de trabalhadores não manuais de rotina nível alto - 13,7\%, totalizando $61,8 \%$ dessas classes na sua população. A renda era média-alta, mas muito inferior à dos espaços da elite (pouco superior à metade). Esses espaços também se apresentavam predominantes como de apartamentos $(43,9 \%)$ e condomínios (2,8\%, a mais alta presença entre os grupos), e dispunham de infraestrutura completa (praticamente igual à do grupo anterior). Essas áreas também apresentaram queda populacional nos anos 1990 taxas negativas de $-0,7 \%$ ao ano, em média, e também recuperaram o crescimento nos anos 2000 (1,2\% aa).

\section{3) Espaços médios-misturados}

Esses espaços tinham características próximas da média da metrópole em quase todos os indicadores, mas proporções levemente acima da média de profissionais, trabalhadores não manuais de rotina nível alto e técnicos e supervisores. A proporção dessa última classe é a mais alta em toda a metrópole. Certamente representavam áreas misturadas, mas com predominância de classes médias e também presença de grupos superiores. Os indivíduos autodeclarados pretos e pardos já alcançam $29 \%$ da população. Em termos gerais, suas características eram um pouco superiores à média em termos de composição social. Os apartamentos eram amplamente minoritários (apenas 22\%), mas as condições urbanas continuavam bastante elevadas e a infraestrutura próxima da universalização. Estes espaços apresentaram quase estabilidade demográfica nos 1990 - taxa média negativa de $0,1 \%$ aa, e crescimento bastante reduzido nos anos 2000 (apenas $0,5 \%$ aa). 


\section{4) Espaços médios-baixos misturados}

Áreas com predominância de trabalhadores manuais (qualificados e não qualificados), mas também não trabalhadores manuais de rotina nível baixo e técnicos e supervisores. Essas quatro classes totalizavam $71,6 \%$ da população. Esses espaços apresentavam a mais elevada presença de trabalhadores não manuais de rotina nível baixo - 18,5\%, e a renda relativa situava-se entre média e baixa. Tratava-se de áreas com características sociais mistas entre classes médias e grupos sociais baixos e com elevada presença de pretos e pardos (44\%). A habitação predominante eram casas (apenas 9\% de apartamentos), e os setores subnormais eram mais frequentes do que a média da metrópole. Esses espaços tiveram crescimento alto nos anos 1990 - 2,8\% aa, e continuaram crescendo nos anos 2000 (1,1\% aa). As condições de infraestrutura eram próximas da média metropolitana ou mesmo melhores do que ela para a maior parte dos indicadores.

\section{5) Espaços dos trabalhadores manuais}

O último grupo apresentava uma elevada e clara predominância de trabalhadores manuais qualificados e não qualificados - 58,9\%. A única outra classe com proporção superior à média metropolitana era a dos trabalhadores não manuais de rotina, nível baixo, com 18,5\%. A renda era muito baixa. A população morava quase sempre em casas $(91,7 \%)$ e os moradores de setores subnormais eram muito frequentes. Indivíduos autodenominados pretos ou pardos eram predominantes 51,7\% (único tipo de espaço com essa predominância), e jovens eram

abundantes. Essas áreas experimentaram explosão demográfica nos anos $1990-6 \%$ aa, e continuaram crescendo a taxas expressivas nos anos 2000 - 1,9\% aa. As condições de infraestrutura eram muito precárias em quase todos os indicadores - apenas $72 \%$ dos domicílios contavam com banheiros de uso exclusivo, $72 \%$ tinham lixo coletado por serviço de coleta e $73 \%$ dos domicílios tinham acesso a serviços de energia elétrica com medidor individualizado. É de se notar que os quatro espaços precedentes apresentavam pequena variação nas condições de infraestrutura, com coberturas altas e próximas às médias da metrópole. O único espaço que discrepava era exatamente o dos trabalhadores manuais, em que todos os indicadores apresentam coberturas inferiores à média (por vezes substancialmente), e os indicadores de precariedade do entorno das habitações indicavam condições muito precárias em 2010. 
Estrutura Social e Segregação em São Paulo

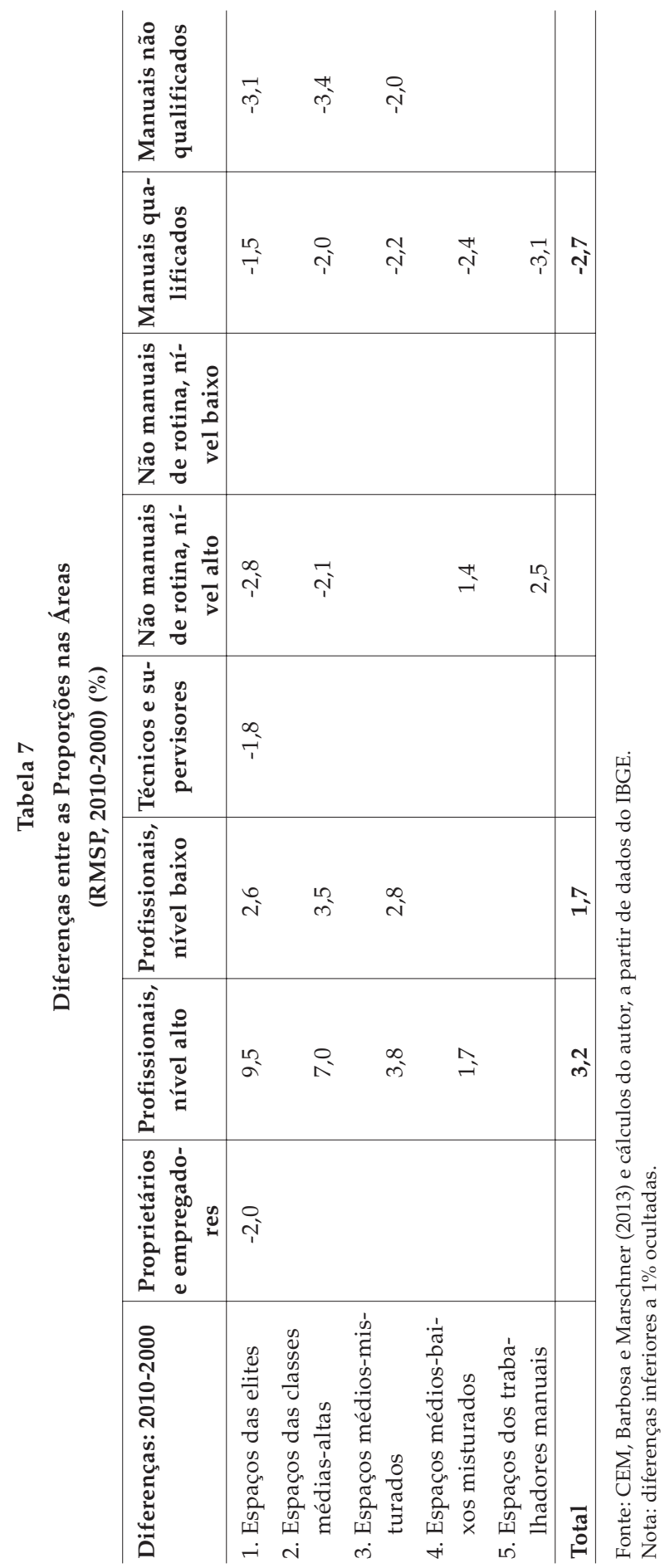

DADOS - Revista de Ciências Sociais, Rio de Janeiro, vol. 57, n 3, 2014 
Mas será que estes espaços já tinham essas características em 2000? Que tipo de transformações ocorreram em termos de conteúdos sociais nesses espaços? Para controlar as mudanças nos conteúdos dos tipos de espaço em cada censo, analisamos as diferenças das classes nos grupos, o que pode nos indicar alterações nas composições sociais destes espaços. A subtração das proporções relativas das classes nas áreas nos censos (Tabelas 4 e 5) resulta nas diferenças apresentadas Tabela 7 (valores inferiores a 1,5\% em módulo foram ocultados, para aumentar a visibilidade).

Como se pode ver, há diferenças substantivas apenas nas classes profissionais, altos e baixos (positivas), e nos trabalhadores manuais (negativas). As classes profissionais aumentaram a sua presença generalizadamente, mesmo onde eram amplamente minoritárias, reforçando as evidências de profissionalização. Simultaneamente, os trabalhadores manuais reduziram sua presença em todos os tipos de espaço, o que certamente se relacionou com o processo de restruturação na indústria já citado.

A mudança mais impressionante, entretanto, foi o tamanho da elevação da presença de profissionais de níveis alto e baixo nos espaços onde essas classes já se encontravam concentradas - espaços das elites e das classes médias-altas. Adicionalmente, é importante assinalar que os trabalhadores manuais não qualificados reduziram mais intensamente a sua presença justamente nesses espaços superiores. Esses espaços, portanto, tornaram-se mais exclusivos ao longo da década. Os trabalhadores manuais qualificados, diferentemente, reduziram mais a sua presença relativa nos espaços inferiores, onde eram predominantes. Estes espaços também sofreram os maiores crescimentos relativos dos trabalhadores não manuais de rotina de nível alto, assim como aumentos não desprezíveis de profissionais. Vale acrescentar que os trabalhadores não manuais de rotina nível baixo apresentavam renda superior à das classes manuais, o que reforça a melhora dos conteúdos sociais médios dos espaços inferiores.

Portanto, sob o ponto de vista dos tipos de espaço, aumentou em geral a presença de profissionais (alto e baixo) e reduziu-se a de trabalhadores manuais (qualificados, mas também não qualificados). As classes superiores tornaram-se ainda mais predominantes nos espaços superiores, mas os espaços inferiores tornaram-se menos operários e manuais, e mais ligados aos trabalhadores não manuais de rotina, assim como a classes superiores. Os espaços inferiores, portanto, se tornam mais heterogêneos. Este resultado é diverso do que seria de se es- 
perar considerando a hipótese da polarização espacial. O caso de São Paulo mostra que um aumento na exclusividade dos espaços de elite pode conviver com maior heterogeneidade dos espaços médios e baixos.

\section{A GEOGRAFIA DOS ESPAÇOS}

Por fim, devemos explorar a geografia destes espaços e de suas transformações. O mapa a seguir mostra a distribuição das classes segundo

\section{Mapa 1}

Distribuição dos Grupos

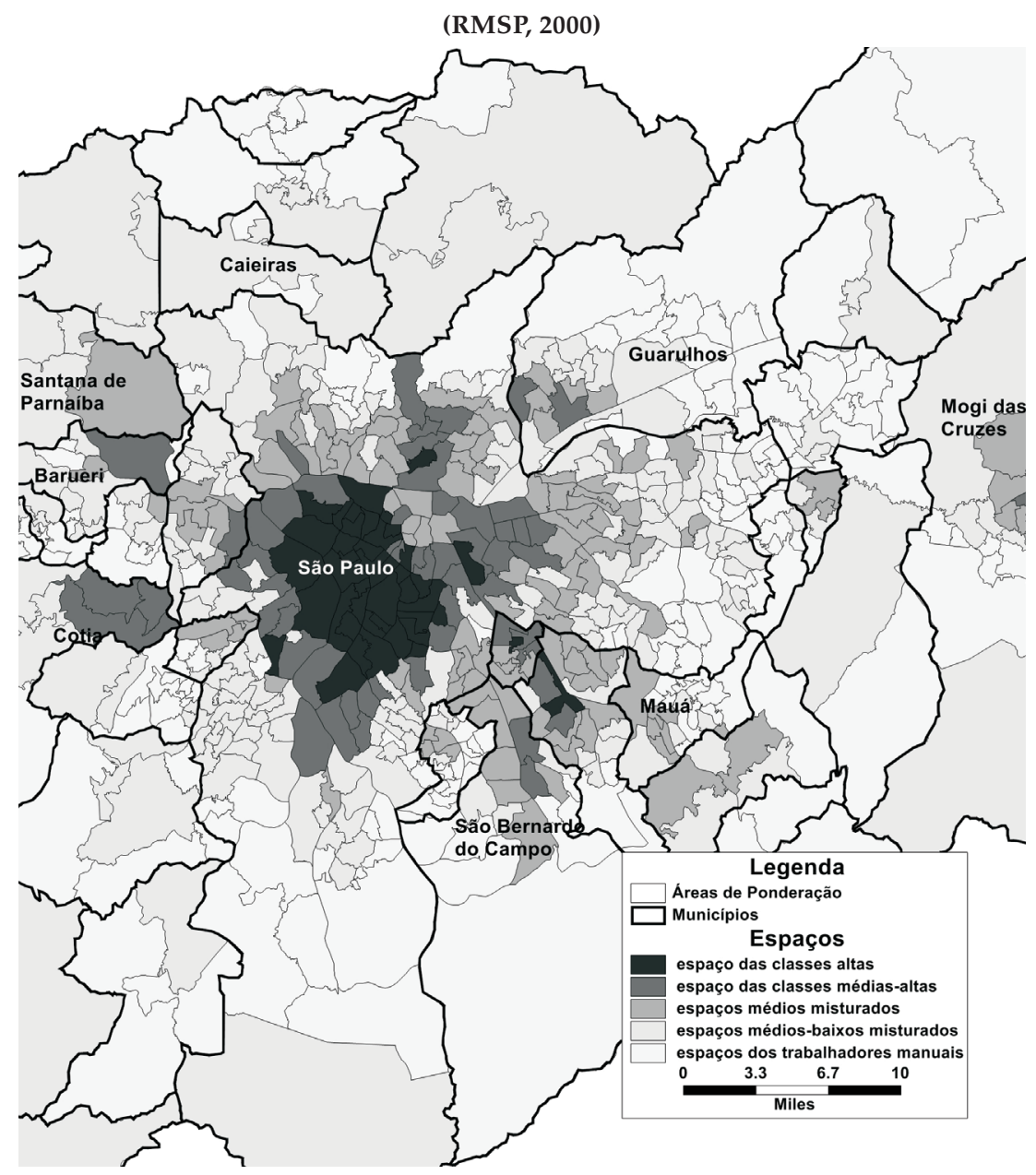

Fonte: CEM e cálculos do autor, a partir de dados do IBGE. 
os tipos de espaço de 2000. Como era de se esperar, o espaço das elites encontra-se fortemente concentrado a sudoeste do Centro Expandido. A sudeste dessa região pode-se ver o espraiamento dos espaços de elite na direção do centro dos municípios mais ricos da região do $\mathrm{ABC}$ paulista - São Caetano, Santo André e, em menor proporção, São Bernardo do Campo. No entorno dessa área de elite, regiões de classe média operam como uma espécie de transição para as áreas periféricas, com significativa heterogeneidade.

No espalhamento dessa região a sudoeste, pode-se observar claramente a favela de Paraisópolis como um espaço de trabalhadores manuais enclavado no território contínuo da elite. E entre as duas manchas contínuas mais escuras a sudeste do Centro Expandido e próximo à fronteira com o Município de São Caetano localiza-se outro espaço manual e médio-baixo misturado, neste caso, o complexo de favelas de Heliópolis /São João Clímaco. Trata-se dos únicos casos de microssegregação de toda a região central, não por acaso as únicas duas favelas de grande porte no Centro Expandido de São Paulo.

A leste e a norte da mancha mais extensa da elite destacam-se as regiões do Tatuapé e de Santana também como espaços de elite, embora de pequenas dimensões. A nordeste e a leste, os centros de Guarulhos e de Mogi das Cruzes aparecem como espaços médios-altos. A oeste, a região dos condomínios fechados sobressai classificada como média-alta e médios-misturados em Santana do Parnaíba, Barueri e Cotia.

O Centro Histórico aparece como espaço predominantemente médio-misturado, imediatamente a nordeste da mancha de elite do Centro Expandido. As regiões mais periféricas, também como esperado, correspondem predominantemente a espaços médios-baixos misturados e manuais, embora com descontinuidades espaciais e substancial presença de espaços médios-misturados, em especial a zona leste do Município de São Paulo.

O Mapa 2 apresenta a mesma informação para os grupos de 2010. Embora a configuração geral dos espaços seja similar, é possível observar importantes mudanças concentradas, destacadas no mapa.

As principais tendências de mudança podem ser resumidas como se segue:

Expansão da mancha de elite do Centro Expandido: a mancha de elite no Centro Expandido aumentou em direção ao sudeste sobre áreas antes 
Mapa 2

Distribuição dos Grupos

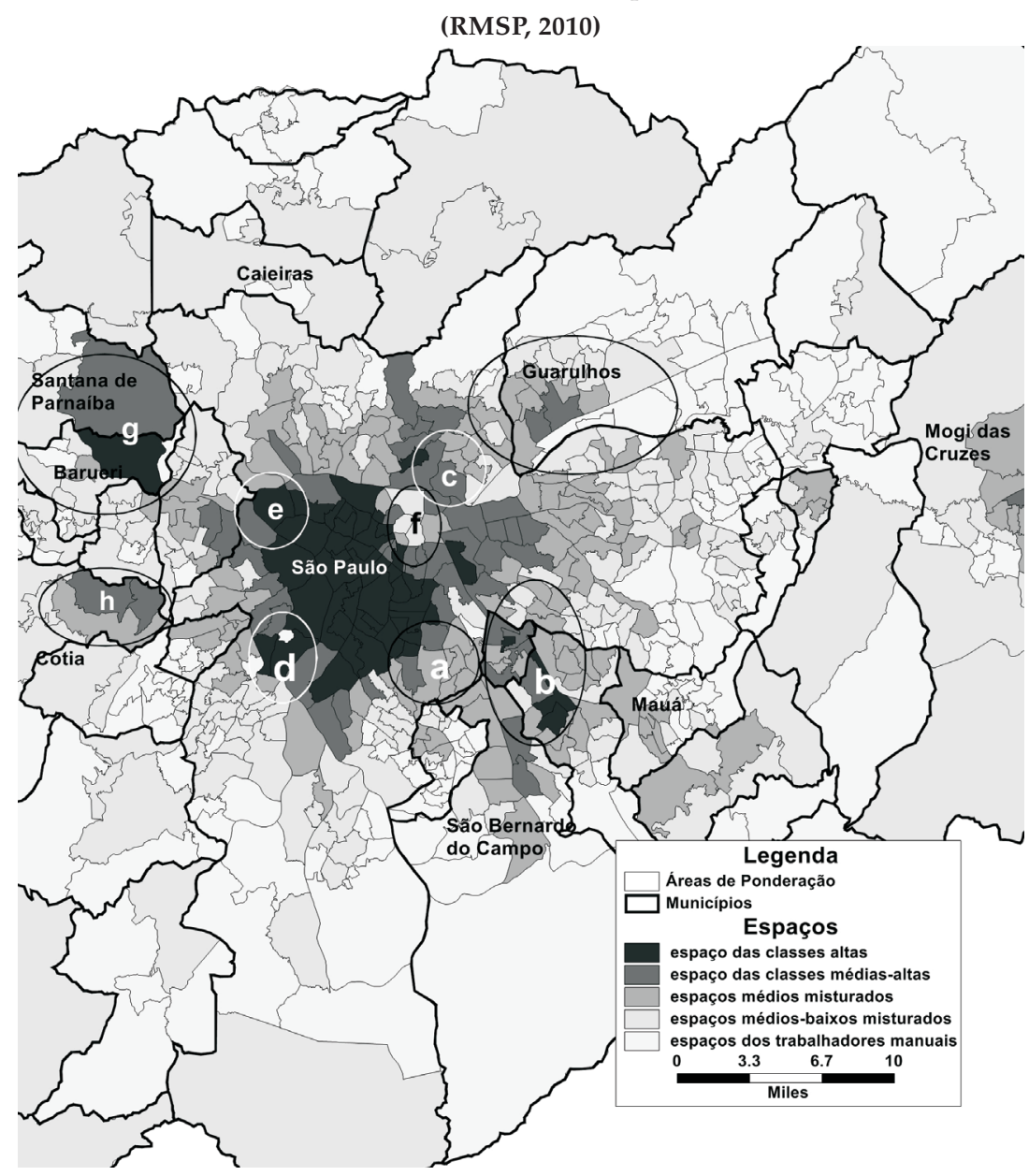

Fonte: CEM e cálculos do autor, a partir de dados do IBGE.

classificadas como médias-altas ("a") em direção ao ABC paulista $\left("{ }^{\prime \prime}\right)$. O mesmo se verificou nas direções oeste e sudoeste na expansão do Morumbi ("d") e a norte ("c") e noroeste da mancha de elite, na Vila Leopoldina (" $\mathrm{e}$ "). Contrariamente ao que seria de se esperar pela literatura sobre a metrópole paulistana, não há efeitos expressivos identificáveis das Operações Urbanas, nem mesmo da Faria Lima/Berrini.

Popularização do Centro Histórico: nesta região, várias áreas que apresentavam em 2000 características de espaços médios misturados se tornaram espaços médios-baixos misturados, sendo, portanto, mais 
populares do que antes (marcada no mapa em negrito como " $\mathrm{f}$ "), confirmando a informação já demonstrada no Mapa 1 relativo à renda.

Condomínios fechados concomitantes com continuidade de periferização: no oeste da região, uma área em Barueri transitou para espaço das classes altas ("g"), enquanto outras nesse mesmo município, assim como em Cotia e em Santana do Parnaíba, tornaram-se espaços das classes médias-altas ("h").

Outras áreas da mesma região fizeram o caminho inverso ao migrar de médias-altas para médias misturadas. No extremo sudoeste do Município de São Paulo, várias áreas antes classificadas como médiasbaixas misturadas tornaram-se manuais, ao mesmo tempo que outras fizeram o caminho contrário. Em Guarulhos, vários espaços tornaram-se mais populares, não muito longe das áreas em elitização já destacadas.

Portanto, as distâncias espaciais entre grupos tenderam a se reduzir, a exemplo dos resultados apontados por Maloutas (2012). Processos de expansão da região mais rica da cidade, de empobrecimento das áreas centrais e de elitização acompanhada de periferização de áreas periféricas coexistiram ao longo da década, tornando a estrutura da metrópole ainda mais complexa, apesar da permanência da segregação.

\section{RESUMINDO TENDÊNCIAS}

É bastante difícil fazer um balanço único de todas essas tendências. De modo geral, é possível dizer que São Paulo é uma cidade bastante segregada, em especial no que diz respeito às classes superiores. As classes médias e inferiores são bem menos segregadas e tendem a coabitar mais frequentemente, mas a estrutura geral da segregação indica uma clara hierarquia entre grupos, apontando para um padrão que poderíamos chamar de evitação social por parte das classes superiores. Ao longo da década, essa estrutura mudou pouco, tanto no que diz respeito aos indicadores de segregação, quanto na distribuição espacial da renda e das classes sociais.

Essa estabilidade é reforçada pela análise geral dos tipos de espaços sociais. Entretanto, a análise dos detalhes da composição dos tipos, assim como a sua distribuição espacial sugerem importantes transformações. Os espaços superiores parecem ter se tornado mais exclusivos em 2010, ao mesmo tempo que espaços manuais e populares se tornaram 
menos operários e mais misturados ao final da década. Os espaços superiores, portanto, se tornaram ainda mais homogêneos, mas os demais espaços da metrópole, inclusive os periféricos, aumentaram a sua heterogeneidade.

A espacialização das informações confirma essa análise, sustentando a presença simultânea de diversas tendências em termos territoriais na década. Se por um lado os dados indicaram expansão da mancha mais rica do Centro Expandido (que tendeu a ficar ainda mais elitizado), áreas do centro velho se popularizaram. Nas amplas periferias da metrópole, tanto processos de elitização (ligados a condomínios, mas não apenas a eles) quanto de continuidade das tendências clássicas de periferização puderam ser observados, tornando a estrutura da metrópole mais heterogênea na década, com periferias mais diversificadas, embora com um Centro Histórico mais popular e espaços de elite mais exclusivos e de maiores dimensões territoriais.

(Recebido para publicação em agosto de 2013)

(Reapresentado em janeiro de 2014)

(Aprovado para publicação em abril de 2014) 


\section{Eduardo Marques}

\section{NOTAS}

1. Para uma interessante discussão de desigualdade com estas informações, ver Barbosa e Prates (2013) e Prates e Barbosa (2013).

2. Vale dizer que os Índices de Moran e os Índices de Dissimilaridade reportados aqui referentes a 2000 são ligeiramente diferentes dos apresentados em Marques, Bichir e Scalon (2012) pela escala geográfica usada para analisar a segregação. No caso daquele estudo, os indicadores foram produzidos com a base de áreas de ponderação de 2000 compatibilizada com 1991, 814 áreas. No caso deste artigo, utilizo uma base de 2000 compatibilizada com 2010. Sobre o efeito metodológico da escala das áreas sobre as medidas de segregação, ver Sabatini (2004).

3. Para dar uma escala para o ID, vale reportar que, para Paris em 1999, o mais alto ID entre grupos linguísticos era observado entre os que falavam francês e os imigrantes turcos-0,47. A grande maioria dos demais índices entre grupos étnicos não ultrapassava 0,4 (Preteceille, 2012). Em Hong Kong em 2006, 0,57 era o Índice de Dissimilaridade entre os decis mais ricos e mais pobres (Yip, 2012). Em Atenas em 2001, 0,40 era o ID entre profissionais de nível alto e ocupações manuais de rotina (Maloutas, 2007).

4. Esses resultados confirmam os achados sobre várias cidades reportados por Maloutas (2012), assim como a análise comparativa do Rio de Janeiro com Paris desenvolvida por Preteceille e Cardoso (2008). Apesar de a segregação ser mais alta no Rio de Janeiro do que em Paris para todas as categorias, é mais elevada para as classes superiores nas duas cidades. Este argumento já havia sido levantado para cidades brasileiras por Villaça (2000) analisando padrões espaciais em mapas temáticos até 1991.

5. É interessante notar que um resultado similar foi encontrado por França (2013) com relação à segregação por raça. Na verdade, a segregação em São Paulo obedece a um claro padrão hierárquico que combina classe e raça, mas onde raça se superpõe à estrutura construída pelas classes, a exemplo do reportado por Maloutas (2012) com relação à dimensão étnica.

6. A grande maioria das áreas de ponderação (93,8\%) foi classificada nos mesmos grupos nos dois censos. A investigação dos 6,2\% restantes, entretanto, nos informa sobre as mudanças espaciais mais importantes, sendo analisada em mapas na próxima seção deste artigo. 


\section{REFERÊNCIAS BIBLIOGRÁFICAS}

ANDERSEN, Hans. (2012), "The Solidity of Urban Socio-Spatial Structures in Copenhagen", in T. Maloutas e K. Fujita (orgs.), Residential Segregation in Comparative Perspective. London, Ashgate.

ANSELIN, Luc. (1995), "Local Indicator of Spatial Association - LISA". Geographical Analysis, vol. 27, pp. 91-115.

BAENINGER, Rosana. (2012), “Crescimento da População na Região Metropolitana de São Paulo: Desconstruindo Mitos do Século XX", in L. Kowarick e E. Marques (orgs.), São Paulo: Novos Percursos e Atores: Sociedade, Cultura e Política. São Paulo, Ed. 34/CEM.

BARBOSA, Rogério e MARSCHNER, Murilo. (2013), “Uma Proposta de Padronização de Classificações em Pesquisas do IBGE (Censos 1960-2010) e PNADs (1981-2011): Educação, Setores de Atividade Econômica e Ocupação (ISCO-88, EGP11 e ISEI)". Working Paper. São Paulo, CEM, Mimeo.

BARBOSA, Rogério e PRATES, Ian. (2013), "Mercado de Trabalho e Estrutura das Desigualdades", in E. Marques (org.), São Paulo, 2000: Espaços, Heterogeneidades e Desigualdades. São Paulo, Ed. Unesp/CEM.

BAUM, Scott. (1999), "Social Transformations in the Global City: Singapore". Urban Studies, vol. 36, no 7, pp. 1095-1117.

BONDUKI, Nabil. (1991), “Depoimento”. Espaço e Debates, no 42, pp. 92-99.

e ROLNIK, Raquel. (1982), “Periferia da Grande São Paulo: Reprodução do Espaço como Expediente de Reprodução da Força de Trabalho", in E. Maricato (org.), A Produção Capitalista da Casa (e da Cidade) no Brasil Industrial (2a ed.). São Paulo, Alfa-Ômega.

BUTLER, Tim. (1997), Gentrification and the Middle-classes. London, Ashgate.

CALDEIRA, Teresa. (2000), Cidade dos Muros. São Paulo, Editora 34.

CAMARGO, Cândido (org.). (1976), São Paulo, 1975 - Crescimento e Pobreza. São Paulo, Loyola.

CAMPOLINA DINIZ, Clélio e CAMPOLINA, Bernardo. (2007), “A Região Metropolitana de São Paulo: Reestruturação, Re-espacialização e Novas Funções”. Revista Eure, vol. XXXIII, no 98, pp. 27-43.

CARVALHO, Inaiá; SOUZA, Ângela e PEREIRA, Gilberto. (2004), “Polarização e Segregação Socioespacial em uma Metrópole Periférica". Cadernos CRH, vol. 17, no 41, pp. 281-297.

CEM (Centro de Estudos da Metrópole). (2004), Mapa da Vulnerabilidade Social da População da Cidade de São Paulo. São Paulo, CEM/Cebrap, SAS/PMSP.

CENTENO, Pablo (org.). (2009), Lima, Diversidad y Fragmentación de una Metrópoli Emergente. Quito, Olacchi.

COMIN, Álvaro e OLIVEIRA, Maria Carolina. (2010), "Southern Cities: Locomotives or Wagons of National Development?" Economic Sociology, vol. 11, no 2, pp. 31-38.

DADOS - Revista de Ciências Sociais, Rio de Janeiro, vol. 57, nº 3, 2014 


\section{Eduardo Marques}

DOMINGUEZ, Marta; LEAL, Jesus e GOYTRE, Elena. (2012), “The Limits of Segregation as an Expression of Socioeconomic Inequality: The Madrid Case", in T. Maloutas e K. Fujita (orgs.), Residential Segregation in Comparative Perspective. London, Ashgate.

DUNCAN, Otis e DUNCAN, Beverly. (1955), “A Methodological Analysis of Segregation Indexes". American Sociological Review, vol. 20, no 2, pp. 210-217.

DUREAU, Françoise e VANEGAS, Andrea. (2009), “Las Diferentes Expresiones del Proceso de Segregación en Bogotá", in S. Jaramillo (org.), Bogotá en el Cambio de Siglo: Promesas y Realidades. Quito, Olacchi.

DURHAM, Eunice. (1988), “A Sociedade Vista da Periferia”, in L. Kowarick (org.), As Lutas Sociais e a Cidade. Rio de Janeiro, Paz e Terra, pp. 169-192.

ERIKSON, Robert; GOLDTHORPE, John e PORTOCARRERO, Lucienne. (1979), “Intergenerational Class Mobility in Three Western European Societies". British Journal of Sociology, vol. 30, pp. 415-441.

FAINSTEIN, Susan. (2008), "Mega-projects in New York, London and Amsterdam". International Journal of Urban and Regional Research, vol. 32, no 4, pp. 768-785.

FARIA, Vilmar. (1992), “A Conjuntura Social Brasileira”. Novos Estudos Cebrap, no 33, pp. 103-144.

FELTRAN, Gabriel. (2011), Fronteiras de Tensão: Política e Violência nas Periferias de São Paulo. São Paulo, Editora Unesp.

FIGUEIREDO, Argelina; TORRES, Haroldo e BICHIR, Renata. (2006), “A Conjuntura Social Brasileira Revisitada". Novos Estudos Cebrap, no 75, pp. 173-184.

FRANÇA, Danilo. (2013), “Desigualdades e Segregação por Raça e Classe”, in E. Marques (org.), São Paulo, 2000: Espaços, Heterogeneidades e Desigualdades. São Paulo, Ed. Unesp/CEM.

FUJITA, Kuniko e HILL, Richard. (2012), "Residential Income Inequality in Tokyo and Why it Does not Translate in Class-Based Inequality", in T. Maloutas e K. Fujita (org.), Residential Segregation in Comparative Perspective. London, Ashgate.

HAMNETT, Chris. (1994), "Social Polarization in Global Cities: Theory and Evidence". Urban Studies, vol. 31, no 3, pp. 401-424.

. (1996a), "Why Sassen Is Wrong: A Response to Burgers". Urban Studies, vol. 33, no 1, pp. 107-110.

(1996b), "Social Polarization, Economic Restructuring and Welfare State Regimes". Urban Studies, vol. 33, no 8, pp. 1407-1430.

KNOX, Paul e TAYLOR, Peter. (1995), World Cities in a World-System. Cambridge, Cambridge University Press.

KOVACS, Zoltán. (2012), "Residential Segregation in Budapest before and after Transition”, in T. Maloutas e K. Fujita (org.), Residential Segregation in Comparative Perspective. London, Ashgate.

KOWARICK, Lúcio. (1979), A Espoliação Urbana. Rio de Janeiro, Paz e Terra.

LEBORGNE, Daniele e LIPIETZ, Alain. (1990), “Flexibilização Defensiva ou Flexibilização Ofensiva", in L. Valladares e E. Preteceille (orgs.), Reestruturação Urbana: Tendências e Desafios. Rio de Janeiro, Nobel/Iuperj. 
MALOUTAS, Thomas. (2007), "Segregation, Social Polarization and Immigration in Athens during the 1990's: Theoretical Expectations and Contextual Difference". International Journal of Urban and Regional Research, vol. 31, no 4, pp. 733-758.

. (2012), "Introduction: Residential Segregation in Context", in T. Maloutas e K. Fujita (orgs.), Residential Segregation in Comparative Perspective. London, Ashgate.

MARICATO, Erminia. (2003), "Metrópole, Legislação e Desigualdade". Estudos Avançados, vol. 17, no 48, pp. 151-166.

MARQUES, Eduardo. (2010), Redes Sociais, Segregação e Pobreza. São Paulo, Ed. Unesp. e BICHIR, Renata. (2003), “Public Policies, Political Cleavages and Urban Space: State Infra-Structure Policies in São Paulo, Brazil -1975-2000". International Journal of Urban and Regional Research, vol. 27, no 4, pp. 811-827.

MARQUES, Eduardo e SARAIVA, Camila. (2005), "As Políticas de Habitação Social”, in E. Marques e H. Torres (orgs.), São Paulo: Segregação, Pobreza Urbana e Desigualdade Social. São Paulo, Ed. Senac.

MARQUES, Eduardo e SCALON, Celi. (2009), "A Dinâmica dos Grupos Sociais em São Paulo na Década de 1990", in C. Scalon (org.), Ensaios de Estratificação. Belo Horizonte, Argumentum.

MARQUES, Eduardo e TORRES, Haroldo (orgs.). (2005), São Paulo: Segregação, Pobreza e Desigualdades Sociais. São Paulo, Editora Senac.

MARQUES, Eduardo; BARBOSA, Rogério e PRATES, Ian. (2013), “Transformações Sócio-econômicas e Estrutura Social", in E. Marques (org.), São Paulo, 2000: Espaços, Heterogeneidades e Desigualdades. São Paulo, Ed. Unesp/CEM.

MARQUES, Eduardo; BICHIR, Renata e SCALON, Celi. (2012), “Residential Segregation and Social Structure in São Paulo: Continuity and Change since the 1990s", in T. Maloutas e K. Fujita (orgs.), Residential Segregation around the World: Why Context Matters. London, Ashgate.

MUSTERD, Sako; MURIE, Alan e KESTELOO, Christian (orgs.). (2006), Neighbourhoods of Poverty: Urban Social Exclusion and Integration in Comparison. London, Ashgate.

PARK, Robert; BURGESS, Ernest e MACKENZIE, Roderick. (1925), The City. Chicago, Chicago University Press.

PÍRES, Pedro. (2009), Buenos Aires, la Formación del Presente. Quito, Olachi.

PRATES, Ian e BARBOSA, Rogério. (2013), "Pobreza e Mercado de Trabalho", in E. Marques (org.), São Paulo, 2000: Espaços, Heterogeneidades e Desigualdades. São Paulo, Ed. Unesp/CEM.

PRETECEILLE, Edmond. (1995), “Division Sociale de l'Espace et Globalization”. Societé Contemporaines, no 22/23, pp. 33-67.

. (2006), “La Ségrégation Sociale a-t-elle Augmenté? La Métropole Parisiense entre Polarization et Mixité". Sociétés Contemporaines, no 62, pp. 37-46.

. (2012), "Segregation, Social Mix and Public Policies in Paris", in T. Maloutas e K. Fujita (orgs.), Residential Segregation in Comparative Perspective. London, Ashgate.

e CARDOSO, Adalberto. (2008), “Río de Janeiro y São Paulo: ¿Ciudades Duales? Comparación con Paris". Ciudad y Territorio, vol. XL, no 158, pp. 617-640.

DADOS - Revista de Ciências Sociais, Rio de Janeiro, vol. 57, nº 3, 2014 


\section{Eduardo Marques}

SABATINI, Francisco. (2004), “Medición de la Segregación Residencial: Reflexiones Metodológicas desde la Ciudad Latino-Americana", in G. Cáceres e F. Sabatini (orgs.), Barrios Cerrados en Santiago de Chile: Entre la Exclusión y la Integración Residencial. Santiago, PUC/Lincoln Institute.

SASSEN, Saskia. (1991), The Global City: New York, London, Tokyo. Princeton, Princeton University Press.

TASCHNER, Suzana e BÓGUS, Lúcia. (2000), "A Cidade dos Anéis: São Paulo", in L. C. de Queiroz Ribeiro (org.), O Futuro das Metrópoles: Desigualdades e Governabilidade. Rio de Janeiro, Revan/Fase.

TORRES, Haroldo. (2005), "Medindo a Segregação", in E. Marques e H. Torres (orgs.), São Paulo: Segregação, Pobreza e Desigualdades Sociais. São Paulo, Ed. Senac.

VAATTOVAARA, Mari e KORTTEINEN, Matti. (2003), “Beyond Polarization versus Professionalization? A Case Study of the Development of the Helsinki Region, Finland". Urban Studies, vol. 40, no 11, pp. 2127-2145.

VALLADARES, Licia e PRETECEILLE, Edmond. (2000), “Favela, Favelas: Unidade ou Diversidade da Favela Carioca", in L. C. de Queiroz Ribeiro (org.), O Futuro das Metrópoles: Desigualdades e Governabilidade. Rio de Janeiro, Observatório/Ed. Revan.

VETTER, David; MASSENA, Rosa Maria e RODRIGUES, Elza. (1979), “Espaço, Valor da Terra e Eqüidade dos Investimentos em Infra-estrutura no Município do Rio de Janeiro". Revista Brasileira de Geografia, vol. 41, no 1/2.

VILLAÇA, Flávio. (2000), Espaço Interurbano no Brasil. São Paulo, Nobel.

WESSEL, Terje. (2000), "Social Polarization and Socioeconomic Segregation in a Welfare State: The Case of Oslo". Urban Studies, vol. 37, no 11, pp. 1947-1967.

YIP, Ngaiming. (2012), "Residential Segregation in an Unequal City: Why are there Urban Ghettos in Hong Kong?", in T. Maloutas e K. Fujita (orgs.), Residential Segregation in Comparative Perspective. London, Ashgate. 


\section{RESUMO}

Estrutura Social e Segregação em São Paulo: Transformações na Década de 2000

Este artigo investiga as transformações da segregação residencial em São Paulo na década de 2000. O trabalho analisa classes sociais geradas a partir da classificação ocupacional EGP, de forma a testar hipóteses presentes sobre a dinâmica recente de classes e espaços. Os dados mostram que a metrópole paulistana continua intensamente segregada e estruturada em torno de um claro padrão de evitação entre grupos sociais posicionados nos polos da estrutura social. Entretanto, embora as transformações dos anos 2000 tenham trazido maior exclusividade às áreas habitadas pelas elites, tenderam a aumentar a heterogeneidade no restante da cidade, contribuindo para maior mistura social nos espaços intermediários e nas periferias.

Palavras-chave: segregação residencial; produção do espaço; estratificação social; São Paulo

\section{ABSTRACT}

Social Structure and Segregation in São Paulo: Transformations in the 2000s

This article analyzes the transformations of residential segregation in the São Paulo metropolitan region in the 2000s. The paper departs from information on social classes generated from the EGP occupational classification in order to test current hypotheses concerning the recent transformations of classes and spaces. The data show that the metropolis continues intensely segregated and structured around a clear avoidance pattern between the social groups positioned at the extremes of social structure. However, although the changes of 2000s brought greater exclusivity for the areas inhabited by the elites, they also tended to increase heterogeneity in the rest of the city, contributing to greater social mix in intermediary spaces and at the peripheries.

Key-words: residential segregation; space production; social stratification; São Paulo 


\section{RÉSUMÉ}

Structure Sociale et Ségrégation à São Paulo: Transformations Pendant la Décennie 2000

Dans cet article, on examine les transformations que la ségrégation du logement à São Paulo a subies pendant la décennie 2000. On y étudie les classes sociales créées à partir du classement des emplois EGP, de façon à vérifier des hypothèses sur la dynamique récente de classes et d'espaces. Les données montrent que la capitale de São Paulo reste fortement scindée et structurée selon un modèle net d'évitement de groupes sociaux situés aux pôles de la structure sociale. Même si les transformations des années 2000 ont amené une plus large exclusivité pour les zones habitées par les élites, par ailleurs l'hétérogénéité s'accroissait pour le reste de la ville, ce qui permettait un plus grand mélange social dans les espaces intermédiaires et dans la périphérie.

Mots-clés: ségrégation du logement; production de l'espace; stratification sociale; São Paulo

\section{RESUMEN}

Estructura Social y Segregación en São Paulo: Transformaciones en la Década de 2000

Este artículo investiga las transformaciones de la segregación residencial en São Paulo en la década de 2000. El trabajo analiza clases sociales generadas a partir de la clasificación ocupacional EGP, de modo a contrastar hipótesis presentes sobre la dinámica reciente de clases y espacios. Los datos muestran que la metrópolis paulistana sigue intensamente segregada y estructurada en torno a un claro patrón de evitación entre grupos sociales posicionados en los polos de la estructura social. Sin embargo, aunque las transformaciones de los años 2000 hayan traído mayor exclusividad a las áreas habitadas por las élites, la heterogeneidad en el resto de la ciudad tendió a incrementarse, contribuyendo para una mayor mezcla social en los espacios intermediarios y en las periferias.

Palabras clave: segregación residencial; producción del espacio; estratificación social; São Paulo 